\title{
Tasting as a Projective Technique
}

Dr Simone Pettigrew, University of Western Australia

Dr Steve Charters, Reims Management School 


\begin{abstract}
Purpose: To investigate the benefits of tasting as a projective technique in explicating consumers' thoughts and feelings towards food and beverage products.

Approach: Ten focus groups were conducted with 35 consumers, 14 wine producers, and 13 mediators. The mediator category included those involved in marketing, wholesaling, retailing, and judging wine. Participants in each focus group were given the same four wines to taste. Initially they were invited to discuss their views on wine quality. The participants were then presented with the wines and asked to discuss their responses to them, particularly their perceptions of the quality of the wines.
\end{abstract}

Findings: The primary findings related to the (1) changes in apparent certainty levels amongst professionals and high-involvement informants, (2) exposure of real and contradictory preferences, (3) role of cognitive, affective, and sensory responses to wine, and (4) interpretation of the language of tasting.

Research implications: Tasting as a projective technique has the potential to generate additional and insightful data that can increase our appreciation of the complexities involved in consumption experiences. In particular, it can reveal the uncertainty that can affect consumers' product evaluations and explicate the multiple evaluation pathways that can be used by consumers of food and beverage products.

Practical implications: The ability of projective techniques to yield both stated and actual preferences provides insight into the salient external factors that impact on consumption decisions and gives an indication of where marketers could most effectively focus their product development and promotional attention.

Key words: projective techniques, tasting, beverages, wine Paper category: Research paper 
The purpose of this article is to discuss the benefits of using tasting as a projective technique in research designed to explore consumers’ thoughts and feelings toward food and beverage products. While tasting is commonly used in the food industry during product development and modification, it is suggested here that when used as a projective technique tasting has the potential to generate data relating to numerous aspects of the consumption experience that cannot be obtained via other means.

Projective techniques (PTs) utilise ambiguous stimuli that require research subjects to be creative in their responses. The idea is that subjects have to project their inner selves into their responses and in the process provide insight into their motivations and feelings. The more traditional PTs include ink blots, picture response, word associations, sentence completion, dialogue bubbles, shopping lists, thematic apperception tests, and mental scenarios (Rook, 1988). More unusual methods involve subjects painting their feelings or reciting their favourite jokes (Richman, 1996). It seems that there are virtually no limits to the stimuli that can be employed in projective exercises (Levy, 1985), and as a result the method may have many potential variations that could be useful to consumer researchers. This article focuses on the process of tasting as a projective method and the insight this approach may generate for marketers of food and beverage products.

A brief background of PTs is provided below, including a discussion of the major benefits and problems understood to be associated with this method of data collection. Examples of consumer research studies that have productively employed PTs are outlined, with particular focus placed on those that have specifically explored the consumption of beverages. The outcomes of a study 
of wine consumption are then used to make a case for the usefulness of tasting as a projective method.

\section{The Use of Projective Techniques}

PTs have long been used in clinical psychology where the emphasis, at least initially, was on diagnosing psychosis. This was achieved by using projection to access the unconscious mind, a process often associated with the work of Sigmund Freud (McGrath, Sherry, and Levy, 1993). In more recent decades, projective methods have been employed in other research areas including marketing. The most well-known marketing research study to use PTs was Haire’s (1950) analysis of housewives' reactions to two shopping lists that differed only in the type of coffee nominated (Nescafe instant coffee versus Maxwell House drip grind). The objective was to explore women's attributions of the imaginary shopper on the basis of the type of coffee purchased. The ground-breaking nature of the study is apparent in the numerous subsequent replications, theoretical reviews, and critical appraisals relating to this study (e.g., Anderson, 1978; Fram and Cibotti, 1991).

Since these early days PTs have enjoyed a varied reputation within marketing. Detractors generally focus their criticisms on a perceived lack of reliability and validity stemming from the subjective nature of instrument development and data analysis. Both advocates and critics note the difficulties associated with interpreting the data generated via PTs (Zober, 1955; Williams, 1958; Yoell and Largen, 1974; Richman, 1996; Hussey and Duncombe, 1999). Given their origins in clinical psychology, there has been debate as to whether researchers without training in psychology can draw meaningful conclusions from projective data. The requirement for 
ambiguous stimuli in instruments means that it is usually not possible to derive the meaning directly from responses (Richman, 1996). As is the case for other qualitative methods, the researcher must make a decision regarding the extent to which responses will be literally interpreted or a deeper meaning sought from the data (Levy, 1985).

Advocates of PTs believe that it is possible for researchers to obtain useful insights from data generated in this way and do not consider a lack of training to be unduly problematic (e.g., Albrecht, 1955). The primary advantage of PTs is the ability of ambiguous stimuli to allow subjects to reveal feelings and conflicts residing in their unconscious minds - data that are not available for examination in other ways (Rook, 1988). In addition, PTs can access information that people may be reluctant to share directly (Rogers and Beal, 1958), and can prevent the superficial rationalisations that may result when interviewees are asked to explain their choices (Haire, 1950; Williams, 1958; Rook, 1988). Consumers often aren’t accustomed to articulating their feelings about products and can respond poorly to direct questioning because they do not have well-formed beliefs on the specific issues of relevance to marketers (Day, 1989). PTs can assist in overcoming these problems by accessing motivations that are not well understood or articulated by consumers (Hussey and Duncombe, 1999).

Other recognised advantages of PTs include their flexibility across a range of topic areas and applications. For example, PTs can be used on their own or as part of focus group discussions (Day, 1989). They can also be cost effective compared to other methods (Fram and Cibotti, 1991), and are often reported to be inherently enjoyable for subjects (Zober, 1955; Rook, 1988).

\section{Projective Techniques in Consumer Research}


While not extensively reported in the literature, PTs have been successfully employed in a wide range of consumer research projects. For example, Aaker and Stayman (1992) used PTs in the form of imaginary leisure-time scenarios involving beer consumption. They explored the associations made between specific brands and leisure activities. More recently, Pettigrew (2002) used a scenario projective technique during interviews to elicit attributions relating to women drinking varying alcoholic beverages.

PTs were also used in Belk, Ger, and Askergaard's (2003) study of the nature of consumer desire. Data collection methods included collages, associations, drawings, and fairy tales along with traditional interviews. According to Belk et al., some of their informants were reluctant or unable to discuss their desires during interviews but were more comfortable responding to the projective stimuli. Similarly, Steele (1964) compared responses to direct and projective questions investigating attitudes to milk. Steele concluded that the projective questions generated more insightful data and served as a useful validity check. Other consumer studies have used PTs to explore non-traditional topics such as male shopping behaviours (Otnes and McGrath, 2001) and gift giving (Mick, Demoss, and Faber, 1992; Sherry, McGrath and Levy, 1993).

As is commonly the case, the studies described above all used scenarios or descriptions (pictorial and verbal) of products and consumption situations to prompt consumers to share their thoughts and feelings on certain topics. According to Yoell and Largen (1974), the testing of subjects away from a normal consumption context is a critical defect of PTs. They suggested that consumer researchers should instead spend time exploring actual use experiences. This raises the question of whether a more direct encounter with a product may constitute an alternative projective 
method that can be effective in generating rich data of value to marketers. Tasting as a PT may more closely mimic the consumption process as normally experienced by consumers and provide enhanced insight into consumption behaviours.

\section{Tasting as a Projective Technique}

In a simplistic form, tasting as a PT is commonly employed in commercial taste tests. These are performed for numerous reasons: to assess the acceptability of the taste of a new product; to determine whether consumers can detect a difference between an organisation's product and a competitor's; to test consistency between batches; and to gauge the taste comparability of an ingredient that is cheaper or has a longer shelf life (Hill, Larsen, and Robinson, 1981; Buchanan, Givon, and Goldman, 1987; Lau, Post, and Kagan, 1995).

Academic studies employing taste tests as a means of generating theoretical insights into consumer behaviour are few in number. One example is Ackoff and Emshoff's (1975) study which established that most drinkers do not understand their own motivations for consuming beer and that the symbolic information provided in mock advertisements, not the taste, was the determining factor for brand preference.

Other studies have used taste tests to assess the extent to which colour affects perceptions of beverage flavour. Garber, Hyatt, and Starr (2000) varied the colour of powdered fruit drinks and found that consumers use colour to make decisions relating to perceived flavour and product preference. Colour dominated both taste and labelling as a flavour cue. A similar study noted that visual cues overrode taste cues when white wine was dyed red (Morrot, Brochet, and 
Dubourdieu, 2001). These outcomes have important implications for marketers in their attempts to focus on those aspects of food and beverage products that are most relevant to the purchase decision.

Given the potential for PTs to explore the consumption process in general and for taste tests to provide insight into the tasting process in particular, employing tasting as a PT holds promise for exploring the consumption of food and beverages where it may be difficult to directly access attitudes and motivations. The highly symbolic nature of food products complicates the consumer research process because of the layers of conscious and unconscious attributions that are made. Levy (1981) suggested that there exists a 'hierarchy' of drinks from the lightest to the darkest and the softest and most nutritious to the strongest and most harmful. He nominated a progression from milk and water at one pole to whisky and brandy at the other. Similarly, Allen and Ng (2003) identified the importance of symbolic meaning in some consumers' meat consumption decisions.

In terms of obtaining accurate data from consumers, Haire (1950) noted that people may be reluctant to discuss important factors affecting beverage purchase decisions if those factors are deemed to be socially embarrassing. He provided the example of 'snob appeal' as a motivation that may be powerful yet understated or concealed. In such cases it is important to tease out both the cognitive and affective aspects of consumers' reactions to products, a task that can be achieved by incorporating tasting into the data collection process (Ghose and Lowengart, 2001). Given these points, wine consumption as a form of consumer behaviour would appear to be wellsuited to the exploration of the effectiveness of tasting as a PT. The importance of conspicuous consumption in wine consumption has been documented (Vigneron and Johnson, 1999; 
Pettigrew, 2003), as has the tendency for wine drinkers to engage in affective and, at times, cognitive evaluative processes during consumption (Charters and Pettigrew, 2006). The following section describes a study that utilised taste testing during focus groups to explore the process of wine consumption.

\section{The Research Study}

The study was an exploratory project designed to examine perceptions of wine quality, particularly with regard to cognitive, affective, and sensory responses to the product. Ten focus groups were conducted with consumers and members of the wine industry to establish consistencies and dissonances in their views on wine quality. Thirty-five consumers, 14 wine producers, and 13 mediators participated in the focus groups (see Table 1 for the participants' characteristics). The mediator category included those involved in marketing, wholesaling, retailing, and judging wine. There were two groups of wine producers and two of mediators. Reflecting their larger population size, six groups were held with consumers.

\section{Insert Table 1 about here}

The groups were structured to ensure different forms of consumption practice in each, roughly equating to involvement level, so that two focus groups were with higher-involvement consumers, two with medium-involvement consumers, and two with lower-involvement consumers. The groups were conducted across three Australian states - New South Wales, South Australia, and Western Australia. The participants were sourced purposively to access those with a range of involvement levels with the product, although all had to be at least occasional wine drinkers. Participants were found primarily by the use of intermediaries who located them 
according to a specific brief. The use of different reference groups comprising consumers with varying involvement levels and the collection of data in different locations constituted a form of triangulation to enhance the validity of the research (Denzin, 1989).

Participants in each focus group were given the same four wines to taste. The bottles were disguised to avoid participants making any judgments about the wines based on extrinsic cues. Several criteria were adopted to ensure appropriate wines were selected, including that the wines should be sufficiently varied to provide some interest for all target groups (so they would provoke some debate) and to allow even the most inexperienced tasters to see distinctions. Additionally, the wines were selected to reflect a range of price levels and therefore cover a variety of purported quality levels.

One area of consideration was the stylistic relationship of the wines to each other. For instance, all of the wines could be made from the same grape variety (say chardonnay) but with a different purported quality level. This would provide a very clear comparative exercise for participants. On the other hand, the four wines could be widely differing in style (for instance, a sparkling wine, a sweet wine, an aged white wine, and a young red wine). This would allow a much better assessment of the participants' views on the discrete evaluation of wine (for each would of necessity be treated in isolation), but would make it more difficult to probe their views on the comparative nature of quality. As a result two wines were selected that could reasonably be viewed as a pair (in this case two sparkling wines) and two that bore no stylistic similarity to the any of the others to allow for discrete consideration. 
The wines selected were a French Champagne, a moderately cheap Australian sparkling wine, an aged (seven year old) New Zealand sauvignon blanc, and a New Zealand pinot noir. These specific choices were made on the basis of their varying levels of evaluation difficulty, their ability to yield dichotomous responses from drinkers, and their structural and stylistic differences that could generate discussion among focus group participants. In addition, one of the wines, the Champagne, was selected on the likelihood that it would be popular with most of the professional participants and therefore give them the opportunity to taste at least one very enjoyable wine as part of the process (which proved to be the case).

The wines were consistently presented in the order listed above for two reasons. First, in professional tastings there is a tendency to move from sparkling to white to red wines. Second, the Champagne preceded the cheaper sparkling wine to avoid the more experienced tasters assuming that the wines went in a simple order of progression from the cheapest to the most expensive. The order of presentation was not varied between groups to preclude any possible variation in hedonic response merely because of the varying progression. In addition, there was a concern about the halo effect whereby the proximity of one wine to another affects judgments about it (Jackson, 2002). It was felt better to limit the impact of the halo effect by ensuring that if it did occur it was always relevant to the same wines. On the basis of the wines selected, it was assumed that experts would consider wines 1 and 4 to be of high to very high quality, wine 2 of mediocre quality at best, and wine 3 to be too old, and possibly defective, though not necessarily undrinkable.

At the start of each focus group, participants were invited to discuss their views on wine quality. They were then presented with the wines and asked to discuss their responses to them, 
particularly in terms of their perceptions of the wines' quality. Following the wine tasting, the participants were asked more explicitly about the evaluative mechanisms they use (if any) in establishing quality and to consider the aesthetic component of wine quality evaluation.

The impact of personal taste on the evaluation of wine and the common use of wine as a marker of status (Vigneron and Johnson, 1999) meant that there was a potential danger of group dominance by one or two individuals. In some of the focus groups this was apparent, requiring action on the part of the moderator to involve some of the less forthcoming participants. The focus groups were audio and video-recorded and subsequent analysis of the visual data indicated that moderation was effective in assuring adequate involvement of all participants.

In addition to the audio and video tapes, field notes were made during each focus group meeting. The recordings and field notes were then transcribed into MSWord. A formalised process was adopted to code the focus groups. In the first instance a draft transcript was prepared from the audiotape that was then compared and corrected against the videotape. The videotape was watched a second time, at which stage non-verbal interactions and responses were noted on the revised transcript. The final transcript was then coded using NUD*IST which facilitated the analysis of each informant's responses separately and the identification of dissonances and correspondences across informants’ stated views and observed behaviours.

The NUD*IST nodes created in the coding process were a combination of theoretical and in vivo codes (Strauss and Corbin, 1990). They were thus based partly on themes generated in the literature review phase of the project and partly on the ideas that emerged throughout data collection and during coding. Analysis commenced with 170 theoretical and demographic nodes, 
expanding to 343 nodes by the end of the analysis phase. This process yielded a series of concepts for investigation and cross-comparison during the post-coding analysis phase. Given the large number of nodes it is not possible to provide a complete list. However, a summary list of the most relevant topics contained in the nodes (listed according to alphabetical order) is presented in the appendix.

Throughout analysis the trustworthiness of the data was regularly considered. This was done by (1) evaluating the responses of each informant against others with similar reported and observed consumption behaviours, (2) assessing consistency of responses between locations, (3) analysing the trustworthiness of responses both by content and behaviour, and (4) reviewing body language and non-verbal signals.

\section{Study Outcomes}

A number of issues of relevance to consumer behaviour arose from the use of wine as a PT. Amongst the most significant were the (un)certainty of professional informants; changing preferences; the role of cognitive, affective, and sensory responses to wine; and the language of tasting. Each of these issues is discussed below.

\section{Certainty}

In the initial discussions of wine quality, one distinctive (and not unexpected) outcome was that while the consumers were often tentative in their ideas about quality (especially lower involvement consumers), the professionals were quite clear about what they considered wine quality to be. When the wines were served, the certainty the professionals expressed earlier began 
to recede. Their voices became quieter and they were much more tentative in their assertions. Some displayed a reluctance to make quick judgments and used delaying tactics. This also was not unexpected as the evaluation of wine - like any quasi-aesthetic product - is not a precise science. It relies on senses that are subject to physiological, cultural, and situational variation (Jackson, 2002). As the wines were masked, the professionals were aware that their own tasting skills, however good, were imperfect and that a loss of status could occur if they were definite in their comments and later found to be incorrect.

This shift from the definite to the tentative represents a move from the objective and 'professional' (the initial display of cognitive expertise) to the subjective which is based on uncertainty and personal opinion. This paradox was also noted with some of the highinvolvement consumers. Day (1989) has noted how PTs can assist in getting past a focus on the objective characteristics of a product to more subjective feelings, and in this study this was a particularly useful benefit of tasting as a PT as it exposed the tendency for professional and highinvolvement consumers to prioritise objectivity in discussion about wine but to emphasise subjectivity when tasting.

\section{Preferences}

Participants were asked to nominate their preferred wine. In a surprising number of instances their choice ran contrary to their own expectations. The following occurred early in one focus group with a professional who selected the Champagne as his preferred wine:

Jeff: Probably if I had a choice of those I would pick the first wine. And sparkling wines are not what I normally choose... The delicacy in sparkling wines is wasted on me. I'm not going to spend \$100 on a French Champagne just to almost miss it. That is just a personal thing with me. Of all the wine styles in the world, to me Champagne is the one most overrated, and it's the one I just can't see the value in. 
Yet Jeff's favourite wine during the tasting was the Champagne. As a single instance this would not have been significant, but this response - stating a preference for one type of wine yet selecting another in the tasting - occurred regularly. Generally it was drinkers who claimed to prefer table wine opting for one of the sparkling wines, but the reverse also transpired. While the wine selection was limited, which would have had an impact on choice, there were a number of participants (especially male) who expressed a inclination to drink red wines - a preference which has been noted as conveying some social cachet in Australia (Allen, 2002). When faced with a specific choice, however, they opted for one of the other three wines.

In highly symbolic products such as wine that can convey so many messages about the consumer (Groves, Charters, and Reynolds, 2000; Demossier, 2004), the split between ideal preference and actual preference is perhaps to be expected. Using tasting research to deconstruct the nature of these preferences and as the starting point for investigations as to how these preferences are established may provide marketers of such products with much needed insight into how consumers engage with their products. The difficulty, however, is that it is unclear how this disparity between ideal and actual preference will manifest in product selection at the point of purchase. Will consumers choose those beverages for which they have a stated preference or those they prefer to drink? This leaves those employing tasting as a projective technique with the dilemma of which data set to prioritise in efforts to predict future purchase behaviours.

\section{Cognitive, affective, and sensory responses}

These three responses relate to the participants' psychological and physiological reactions to the wines tasted. Different drinkers can take varying initial approaches, adopting either a primarily cognitive, affective, or sensory approach (Charters and Pettigrew, 2006). The use of tasting as a 
PT facilitated the observation of varying processing pathways through the analysis of body language and visual expression while generating verbal responses to direct questions. Relevant body language included facial expressions of pleasure, disgust, and pensiveness and bodily recoil or openness.

No participant used any approach discretely; rather, there were interaction effects so that what may have been initially sensed was subsequently cognitively analysed with an emotional response following. An alternative pathway, which occurred often among high-involvement drinkers, involved a focus on mental analysis before an apparent sensory or affective response.

\section{Language}

Many words were used by participants to describe the wines offered. Some words were very commonly used, such as the term 'smoothness' which was often used by lower involvement participants as an epithet of approbation. However, smoothness as a concept was difficult for the participants to pin down. It was perceived to have aspects of flavour but also involved the tactile qualities of the wine. Overall, there did not seem to be a common understanding of smoothness. The following occurred in one consumer group:

Hetty: The fourth [wine] I think was quite a smooth red.

Alison: I just disagree with everybody about the red. I didn't find that an enjoyable red to drink...It felt a bit dry to me - like it leaves me with a dry taste. And a few people said 'smooth' - and I didn't find it smooth at all. I agree it's spicy and a bit peppery.

Ingrid: I agree with you.

Informants were asked to explain what they meant by smoothness but were not able to reach a common interpretation. As the disagreement between Hetty and Alison shows, it seemed that 
there were two unresolved problems with the word. First, the physiological perception of smoothness varied between participants. Additionally, the primary sensation that gave rise to the notion of smoothness varied from individual to individual. In another focus group, four participants used the word at varying times in reference to three different characteristics: the absence of bitterness, astringent tannin, and vinegary characters in the wine. At one time a sparkling wine was praised for being smooth, presumably because of the fineness of its effervescence. The use of tasting as a PT thus identified the use of common terms that can have little consensus in interpretation from drinker to drinker.

\section{Discussion}

This article explored the extent to which tasting can constitute an effective PT. The findings of the study demonstrate that tasting can be useful for generating a more nuanced appreciation of how consumers engage with a product. The variations between confident assertion and actual uncertainty and between professed and real preferences were exposed, along with different sensory and cognitive responses. The use of PTs later in the focus groups supplemented the more cognitive data generated during the earlier stages of the groups and illustrated the benefits of using PTs over merely obtaining self-report data. The combination of approaches yielded additional layers of understanding that would not otherwise have been achieved.

The study has implications for marketers’ attempts to influence the marketplace. For example, differences in certainty between reported attitudes and reactions during consumption highlight the dangers of taking self-report data at face value and reinforce the benefits of more naturalistic research methods. These differences in certainty also underscore the case by case nature of 
consumer evaluations in the food and beverage industries where products can vary considerably between batches. Suppliers are only as good as the last bottle or meal they sell.

The ability of PTs to yield both stated and actual preferences provides insight into the salient external factors that impact on consumption decisions and gives an indication of where marketers could most effectively focus their product development and promotional attention. Similarly, understanding the extent to which product-related language is shared among consumers offers marketers a working vocabulary to employ in their communications. It also identifies possible areas of consumer education to increase consumer engagement with the product. Finally, appreciating the existence of varying evaluation pathways may enable segmentation of customers on the basis of their invoked pathway and the development of appropriate communications to appeal to the dominant processing approach of each segment.

In terms of methodological and theoretical contributions, the study demonstrates how tasting can generate different data to that obtained by other means (as per Steele, 1964; Belk et al., 2003). Tasting is closer to a real consumption context than self-reports and thus allows researchers to glimpse how the process of product evaluation occurs in situ. This may enhance our understanding of consumer behaviour by circumventing consumers’ presentational behaviours and superficial rationalisations (Haire, 1950; Williams, 1958; Rook, 1988). For example, the rational decision making model that has been the bedrock of the consumer behaviour discipline can be queried on the basis of drinkers' uncertainty and change in stated preferences when participating in a tasting activity. 
The study also demonstrates the relative ease with which projective responses can be triggered and interpreted (as per Rook, 1988). Even low-involvement participants were able to comfortably engage in projective behaviours during the wine tasting activity. While interpretation of the data called for insight and creativity as typically required in qualitative data analysis, it did not constitute a difficult task. It was indeed a more complex process as both verbal and physical data needed to be analysed in detail and decisions had to be made about the relative importance of the sometimes contradictory data sets that were generated. The superior insight obtained from the process, however, more than compensated for the additional effort involved.

To conclude, tasting as a projective technique has the potential to generate additional and insightful data beyond that obtained via other means. In particular, it can increase our appreciation of the complexities of consumption experiences by revealing the uncertainty that can affect consumers’ product evaluations. These evaluations were found to be multi-factorial in nature and, as a result, capable of triggering multiple evaluation pathways. The limitations of projective techniques that have been highlighted by detractors of the method were not found to be problematic in this study. On the contrary, the findings from the projective exercise appeared to have greater validity than the responses provided to direct questions and the interpretation of the data was not found to be overly difficult. 


\section{References}

Aaker, D.A. and Stayman, D.M. (1992), “Implementing the concept of transformational advertising”, Psychology \& Marketing, Vol. 9, No. 3, pp. 237-53.

Ackoff, R.L. and Emshoff, J.R. (1975), “Advertising research at Anheuser-Busch, Inc. (196874)”, Sloan Management Review, Spring, pp. 1-15.

Albrecht, P.A. (1955), “Projective methods in industry”, Journal of Business, Vol. 28, No. 1, p. 18.

Allen, M. (2002), “A matter of opinion”, Harpers, Australia supplement, January, pp. 24-25.

Allen, M. W., and Ng, S. H. (2003), "Human values, utilitarian benefits and identification: the case of meat”, European Journal of Social Psychology, Vol. 33, pp. 37-56.

Anderson, J.C. (1978), “The validity of Haire's shopping list projective technique”, Journal of Marketing Research, Vol. 15, pp. 644-49.

Belk, R.W., Ger, G. and Askergaard, S. (2003), “The fire of desire: a multisited inquiry into consumer passion”, Journal of Consumer Research, Vol. 30, No. 3, pp. 326-51.

Buchanan, B., Givon, M. and Goldman, A. (1987), "Measurement of discrimination ability in taste tests: an empirical investigation”, Journal of Marketing Research, Vol. 24, No. 2, pp. 154-63.

Charters, S. and Pettigrew, S. (2006), "Product involvement and the evaluation of wine quality”, Qualitative Market Research, Vol. 8, No. 4, pp. 181-93.

Day, E. (1989), “Share of heart: what is it and how can it be measured?”, Journal of Consumer Marketing, Vol. 6, No. 1, pp. 5-12.

Demossier, M. (2004), “Contemporary lifestyles: the case of wine” in Sloan, D. (Ed.), Culinary Taste: Consumer Behaviour in the International Restaurant Sector, Elsevier ButterworthHeinemann, Oxford, pp. 93-108. 
Denzin, N.K. (1989), The Research Act, Prentice-Hall, Englewood Cliffs.

Fram, E.H. and Cibotti, E. (1991), “The shopping list studies and projective techniques: a 40-year view”, Marketing Research, Vol. 3, No. 4, p. 14.

Garber, L., Hyatt, E.M. and G. Starr, R.G. (2000), “The effects of food color on perceived flavor”, Journal of Marketing Theory and Practice, Vol. 8, No. 4, pp. 59-72.

Ghose, S. and Lowengart, O. (2001), “Taste tests: impacts on consumer perceptions and preferences on brand positioning strategies”, Journal of Targeting, Measurement and Analysis for Marketing, Vol. 10, No. 1, pp. 26-41.

Groves, R., Charters, S., and Reynolds, C. (2000), “Imbibing, inscribing, integrating and imparting: a typology of wine consumption practices”, Journal of Wine Research, Vol. 11, No. 3, pp. 209-23.

Haire, M. (1950), “Projective techniques in marketing research”, Journal of Marketing, Vol. 14, No. 5, pp. 649-56.

Hill, R. D., Larsen, T. J., and Robinson, P. W. (1981), “The effects of environment on taste discrimination of bread spreads”, Journal of Advertising, Vol. 10, pp. 19-24.

Hussey, M. and Duncombe, N. (1999), "Projecting the right image: using projective techniques to measure brand image”, Qualitative Market Research, Vol. 2, No. 1, pp. 22-30.

Jackson, R.S. (2002), Wine Tasting: A Professional Handbook. Academic Press, London.

Lau, K-N., Post, G. and Kagan, A. (1995), "Using economic incentives to distinguish perception bias from discrimination ability in taste tests”, Journal of Marketing Research, Vol. 32, No. 2, pp. 140-63.

Levy, S. J. (1981). Interpreting consumer mythology: A structural approach to consumer behavior. Journal of Marketing, 45(Summer), 49-61. 
Levy, S.J. (1985), “Dreams, fairy tales, animals, and cars”, Psychology \& Marketing, Vol. 2, No. 2, pp. 67-81.

McGrath, M.A., Sherry, J.F. and Levy, S.J. (1993), “Giving voice to the gift: the use of projective techniques to recover lost meanings”, Journal of Consumer Psychology, Vol. 2, No. 2, pp. 171-91.

Mick, D.G., Demoss, M. and Faber, R.J. (1992), “A projective study of motivations and meanings of self-gifts: implications for retail management”, Journal of Retailing, Vol. 68, No. 2, pp. 122-44.

Morrot, Gil, Brochet, F., and Dubourdieu, D. (2001), “The color of odors”, Brain and Language, Vol. 79, pp. 309-20.

Otnes, C. and McGrath, M.A. (2001), "Perceptions and realities in male shopping behaviour”, Journal of Retailing, Vol. 77, pp. 111-37.

Pettigrew, S. (2002), “Consuming alcohol” in Miles, S., Anderson, A., and Meethan, K. (Eds.), The Changing Consumer: Markets and Meanings, Routledge, UK.

Pettigrew, S. (2003), “Wine consumption contexts”, International Journal of Wine Marketing, 15, 2, pp. 37-45.

Richman, J. (1996), “Jokes as a projective technique: the humor of psychiatric patients”, American Journal of Psychotherapy, Vol. 50, No. 3, pp. 336-46.

Rogers, E.M. and Beal, G.M. (1958), “Projective techniques in interviewing farmers”, Journal of Marketing, Vol. 23, pp. 177-79.

Rook, D.W. (1988), "Researching consumer fantasy”, Research in Consumer Behavior, Vol. 3, pp. 247-70.

Sherry, J.F, McGrath, M.A. and Levy, S.J. (1993), “The dark side of the gift”, Journal of Business Research, Vol. 28, pp. 225-44. 
Steele, H.L. (1964), “On the validity of projective questions,” Journal of Marketing Research, Vol. 1, No. 3, pp. 46-49.

Strauss, A., and Corbin, J. (1990), Basics of Qualitative Research. Sage, California.

Vigneron, F. and Johnson, L.W. (1999), “A review and a conceptual framework of prestigeseeking consumer behavior”, Academy of Marketing Science Review, Vol. 1999, No. 1, pp. 1-23

Williams, P. (1958), “Consumer research with projective techniques”, Journal of Marketing, Vol. 22, pp. 112-14.

Yoell, W.A. and Largen, R.G. (1974), “The fallacy of projective techniques”, Journal of Advertising, Vol. 3, pp. 33-46.

Zober, M. (1955), “Some projective techniques applied to marketing research”, Journal of Marketing, Vol. 20, pp. 262-68. 


\section{Appendix}

Node summary list (in alphabetical order)

\begin{tabular}{|c|c|c|}
\hline Parent nodes & Level 1 child nodes & Level 2 child nodes \\
\hline \multirow[t]{3}{*}{ Approach } & Affective & \\
\hline & Cognitive & \\
\hline & Sensory & \\
\hline \multirow[t]{3}{*}{ Assessing quality } & Processes used & \\
\hline & Situation & \\
\hline & Role of language & Comprehensibility \\
\hline \multirow[t]{2}{*}{ Concept of quality } & Objective/subjective & Preference \\
\hline & Difficulty & \\
\hline \multirow[t]{9}{*}{ Motivations for wine consumption } & Enjoyment & Alcohol content \\
\hline & & Diversity \\
\hline & & Intellectual challenge \\
\hline & & Taste \\
\hline & Meal accompaniment & \\
\hline & Relaxation & \\
\hline & Self-image & \\
\hline & Situation & \\
\hline & Tradition/culture & \\
\hline \multirow[t]{2}{*}{ Nature of quality } & Technical factors & \\
\hline & Quality dimensions & Appearance \\
\hline
\end{tabular}




\begin{tabular}{|l|l|l|}
\hline & & Gustatory issues \\
\hline & & Quality as representation \\
\hline Participant characteristics & Age/gender/location & \\
\hline & Consumption frequency & \\
\hline & Involvement level & \\
\hline Perceived relevance of quality & High/medium/low & \\
\hline & First/repeat purchase & \\
\hline Quality cues & Situational variables & \\
\hline & Intrinsic & Terroir \\
\hline & Extrinsic & Price \\
\hline Stated preferences & & Packaging \\
\hline & Before tasting & \\
\hline & After tasting & \\
\hline & & \\
\hline & & \\
\hline & & \\
\hline & & \\
\hline
\end{tabular}


Table 1: Sample profile

\begin{tabular}{|c|c|c|}
\hline Attributes & & Number of informants \\
\hline \multicolumn{3}{|l|}{ Gender } \\
\hline & Men & 34 \\
\hline & Women & 28 \\
\hline \multicolumn{3}{|l|}{ Age } \\
\hline & $18-25$ & 3 \\
\hline & $26-44$ & 43 \\
\hline & $45+$ & 16 \\
\hline \multicolumn{3}{|l|}{ Status } \\
\hline & Consumer & 35 \\
\hline & Mediator & 13 \\
\hline & Producer & 14 \\
\hline \multicolumn{3}{|l|}{ Location } \\
\hline & Western Australia & 26 \\
\hline & South Australia & 13 \\
\hline & New South Wales & 23 \\
\hline \multicolumn{3}{|l|}{ Involvement level } \\
\hline & Low & 17 \\
\hline & Medium & 13 \\
\hline & High - consumer & 5 \\
\hline & High - professional & 27 \\
\hline Total & & 62 \\
\hline
\end{tabular}

